district, and numerous small townships. A local company in Larne owns the power station and a Belfast company the overhead distribution system.

\section{Atmospheric Effects and the Andean Eruptions}

WHEN a solar halo and sun pillar were observed in London a few days after the recent volcanic outbreaks in the Andes, the question of a connexion between the two phenomena was raised. There was no serious case to be made out for any such connexion, in view of the enormous distance that separates Great Britain from the scene of the eruption, and the incredible wind velocity that would have been necessary to bring volcanic dust in such a short time. Moreover, optical phenomena of this kind are known to be due to ice crystals at great heights and not to dust. The more rational question of ultimate meteorological effects in the northern hemisphere is discussed in a recent bulletin from Science Service, Washington, D.C. We are reminded that after the explosion of the East Indian volcano Krakatoa in $\mathbf{1 8 8 3}$, volcanic dust drifted entirely round the earth, and that the remarkable red sunsets that occurred for several years after can reasonably be attributed to the presence of this dust, for the selective absorption effects of dust upon the constituent colours of the light of the sun is proved at almost every fine sunset in industrial regions. Prof. W. J. Humphreys, of the U.S.A. Weather Bureau, has expressed the opinion that it is only on the supposition that the ash has ascended in large quantities above the level of the highest clouds that it may be expected to cross over to the northern hemisphere; if confined to lower layers, it may perform long journeys in the atmospheric circulation of the southern hemisphere but will tend to be entangled by condensing cloud particles and be brought to the earth by rain. Apart from sunset effects, the probable influence of dust at very high levels upon the weather through weakening of the solar radiation is difficult to estimate, owing to the complexity of the reactions likely to be set up.

\section{Funerary Offerings from Ancient Mexico}

А томв deposit described as second only in intrinsic value to the recently discovered treasure of Monte Alban, we learn from a recent Science Service bulletin, has been discovered at Texmelincan, in the State of Guerrero, one hundred and twenty miles south of Mexico City. The tomb is situated in an area covered with mounds concealing buildings and other remains. The objects in the tomb have now been deposited in the Department of Archæology, Mexico City. Among them the most notable is a disc of gold, eight inches in diameter, with a hole in the centre. On it are engraved two of the characteristic feathered serpents, intertwined, and with the head of an armed warrior protruding from the jaws of each. Two belts, two feet long and three inches wide, are covered with a thin sheeting of beaten gold. There were also found large gold ear-rings, a necklace of thirty-two hollow gold beads and one of seventy-one unusually fine carved jade beads, three necklaces of shell and stone beads, copper bells, and obsidian ear-rings painted red. Some finely polished pottery vessels suggest a Toltec origin. The nearest important city site, it is pointed out, is Xochicalco, which is noted for its 'Toltec Maya' style.

\section{The Rebuilding of Napier and Hastings}

The New Zealand correspondent of the Times, in the issue for May 5, has given an interesting account of the rebuilding and repair of the towns damaged by the Hawkes Bay earthquake of Feb. 3, 1931. The total loss was estimated at about six million pounds. One-quarter of this amount was provided by the Government, and public subscriptions added nearly $£ 350,000$. In Napier, nearly the whole of the business quarter was destroyed. The work of reconstruction includes the widening and replanning of many streets, the laying down of about 20 miles of main sewers, and the provision of new artesian wells or the repair of old ones sufficient to give a supply of four million gallons daily. An unexpected gain from the earthquake is an extensive area of new land. Before the earthquake, plans had been made to reclaim certain shallow parts of the harbour. This work is now unnecessary, as the earthquake raised the level of the land by five or six feet. About 7000 acres of the new land, it is proposed, will be converted into farm. ing land, and the long marine parade will be widened and beautified.

\section{Announcements}

Sir Arthur Ketth will deliver the Stephen Paget memorial lecture at the annual general meeting of the Research Defence Society, which is to be held on Wednesday, June 15, at 3 P.M., in the lecture hall of the London School of Hygiene and Tropical Medicine, Keppel Street, W.C.1.

Applications for grants from the Research Fund. of the Chemical Society must be made by June 1 on a special form obtainable from the Assistant Secretary, Chemical Society, Burlington House, W.1. Attention is directed to the fact that the income derived from the donation of the Goldsmiths Company is more or less especially devoted to research in inorganic and metallurgical chemistry, and that from the Perkin Memorial Fund to investigations relating to problems connected with the coal-tar and allied industries.

Ar the annual general meeting of the Challenger Society held on April 27, a resolution to the following effect was carried unanimously: "That a sum of money, provisionally put at $£ 25$, to be modified at the discretion of the Committee, should be devoted to the assistance of a desirable student (or students) to enable him (or them) to work at Plymouth (or other Marine Biological Station). Preference to be given to members of the Society, and the selection to be in the hands of the Committee."

THE following appointments have recently been made by the Secretary of State for the Colonies in the Colonial agricultural and forest services : Mr. E. Ballard, to be Government entomologist, Palestine ; Mr. E. D. Hill and Mr. W. R. Hudson, inspectors of plants and produce, Gold Coast, to be senior inspectors; Mr. R. R. Staples, agricultural economist, Tanganyika Territory, to be pasture research officer, 